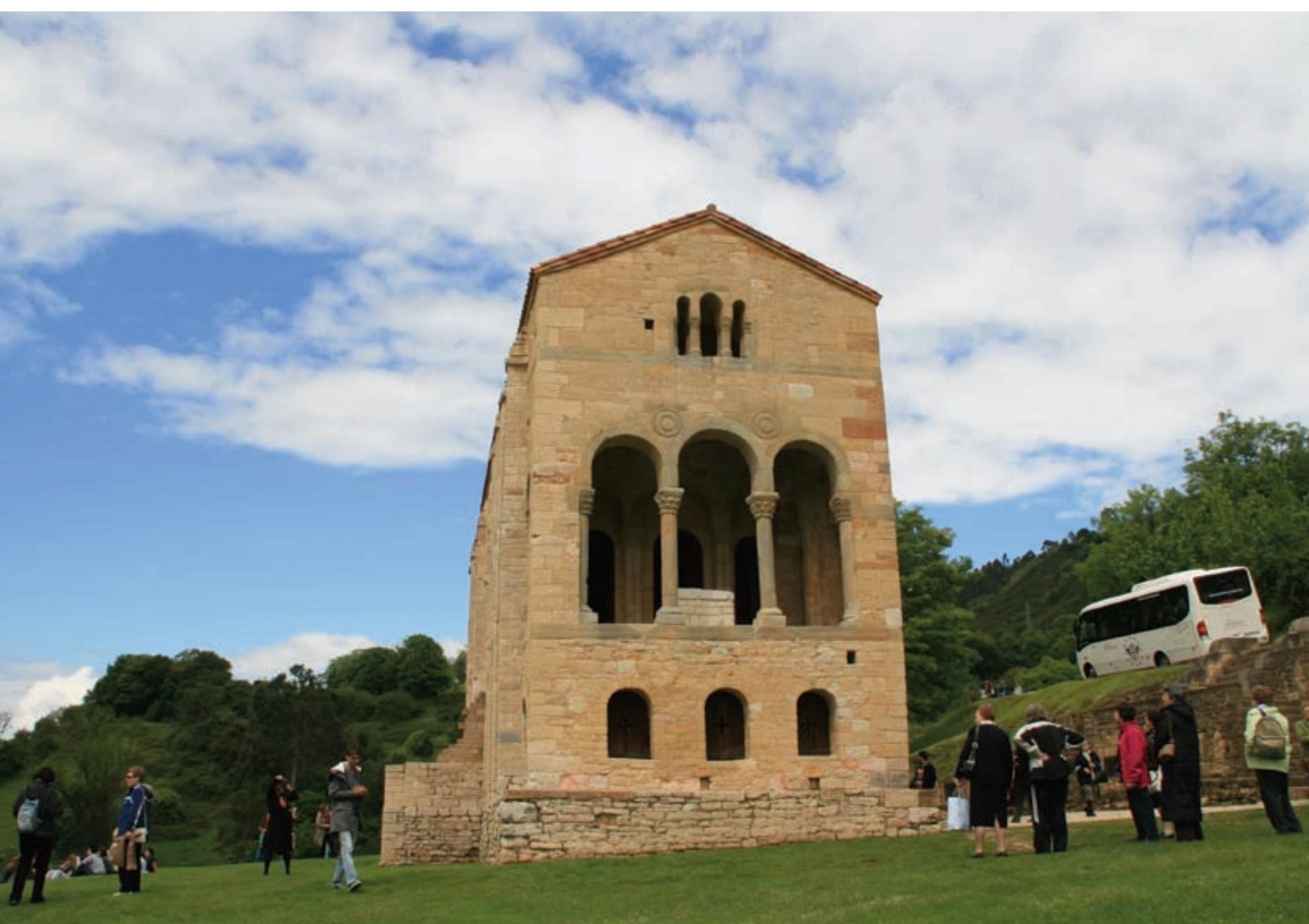

El patrimonio cultural constituye en la actualidad un símbolo de identidad para la sociedad. Iglesia de Santa María del Naranco, Oviedo. Foto: Víctor Fernández Salinas 


\section{El Patrimonio: entre la memoria y la identidad de la Modernidad}

Almudena Hernando Gonzalo, Facultad de Geografía e Historia, U. Complutense de Madrid

\section{Resumen}

Este texto defiende que el patrimonio cultural tiene una función social que trasciende la de la conservación de elementos de cultura especialmente valiosos o significativos. Sostiene que las manifestaciones culturales catalogadas como patrimonio constituyen símbolos del grupo al que pertenecemos, evidencia de nuestra inclusión en una instancia colectiva de identidad a través de la cual neutralizamos la impotencia y la angustia en que nos sumiria la percepción de nosotros mismos como seres aislados frente al mundo.

A diferencia del modo en que construyen la identidad los miembros de sociedades de menor complejidad socio-económica, los seres humanos de la Modernidad depositan en el "yo" la pretensión de autonomía e independencia frente a una realidad que es inabordable. Si dicha fantasia se puede sostener es porque paralelamente a su desarrollo fueron generándose mecanismos que, de forma inconsciente, potenciaban la idea de protección, pertenencia y vinculo. Es decir, que asumian la función que en las sociedades pre-modernas cumplian los mitos, para lo cual deben adoptar su misma estructura cognitiva: representar a una instancia protectora cuya memoria se cuenta a través de referencias espaciales y no temporales. La noción de patrimonio cultural es uno de esos mecanismos, imprescindibles para la construcción de la identidad en la Modernidad.

\section{Palabras clave}

Historia / Identidad / Memoria / Mito / Patrimonio cultural 


\section{INTRODUCCIÓN}

El concepto y la protección del patrimonio cultural aparecen asociados al surgimiento del estado-nación en la Modernidad, paralelamente al estatus de ciudadano para los miembros del grupo social. Bajo la categoría de patrimonio se da acogida a una serie de manifestaciones culturales que representan la esencia histórica de dicho estado, el núcleo de aquello que se considera sus claves constituyentes. Cuando apareció, el concepto de patrimonio emanó de las propias instituciones del estado, que no compartía con la base popular la preocupación por su protección o conservación (BABELON; CHASTEL, 2000). Sin embargo, esta preocupación fue generalizándose a capas progresivamente amplias de la población en relación directa con el aumento de las clases medias, hasta llegar al dia de hoy en que el concepto parece indisociable del imaginario colectivo. En este trabajo se pretende analizar la función que la noción de patrimonio cultural cumple en el seno de la sociedad moderna en tanto que elemento cohesionador de un conjunto social crecientemente individualizado que, a diferencia de las etapas pre-modernas previas, dejó de encontrar en dios, la realeza o la nobleza un marco protector garante de su supervivencia. Se propone un análisis de la función que puede haber cumplido la noción de patrimonio en el seno de la sociedad moderna desde el punto de vista emocional y subjetivo, y de las razones por las que no existe el concepto en ninguna sociedad ajena a la Modernidad. Se pretende demostrar que la labor que el patrimonio desempeña en la Modernidad tiene una trascendencia que sólo puede comprenderse si se analizan los factores inconscientes que entran en juego en la construcción de la identidad humana, aspecto que no suele ser tratado al analizar su génesis, desarrollo y previsiones futuras.

Como iremos viendo, la noción de patrimonio es indisociable del desarrollo de la individualidad como forma de identidad, así que sólo aparecerá en aquellos ambientes sociales definidos por una cierta formación intelectual y profesional. Pero la clave de esta asociación no es, desde el punto de vista identitario, la sensibilidad estética o artística que quepa atribuir a esos "individuos", sino la necesidad que tienen de reconocerse a sí mismos como parte de un grupo para sentir seguridad frente al mundo. Esto explica que la protección del patrimonio interesara, inicialmente, sólo a algunos hombres -aquellos burgueses ilustrados que abanderaban la idea de patria-nación y presidian las instituciones-, pero que a medida que la individualidad se fue generalizando como forma de identidad en crecientes porcentajes de la población (la llamada "clase media") y tanto en hombres como en mujeres, haya ido extendiéndose poco a poco a muchos más miembros del grupo social.

\section{LA FANTASÍA DE LA INDIVIDUALIDAD}

Para entender la función que juega el patrimonio en la construcción de nuestra identidad, hay que comenzar por decir que la realidad en la que vivimos es tan compleja, tan inabarcable, que si los seres humanos fuéramos conscientes de nuestra pequeñez y de nuestra impotencia, la angustia nos bloquearia y nos impediría sobrevivir. Para que esto no suceda, hemos desarrollado una serie de mecanismos que nos permiten creer que somos fuertes, que estamos seguros y que controlamos en medida suficiente la realidad en la que vivimos, sea cual sea el control material real que tengamos sobre ella. Estos mecanismos -que no son otros que los mecanismos de la identidad- varían, pero pasan siempre por sentir una fuerte vinculación con el grupo al que pertenecemos y por confiar en que nuestra supervivencia personal depende del esfuerzo colectivo del conjunto. Sólo así conseguimos sentirnos mínimamente fuertes y seguros frente a ese mundo inconmensurable; sólo así conseguimos un refuerzo de identidad que nos permite superar la sensación de impotencia que nos invadiría si realmente nos tuviéramos que enfrentar de forma aislada a este inabordable universo en el que vivimos. Ahora bien, esta necesidad irrenunciable de vinculación con el grupo no siempre se reconoce de manera explícita y consciente, de lo que no debe deducirse que, cuando no se reconoce, no exista o no se "actúe" de forma inconsciente. De hecho, como veremos, la individualidad es una forma de identidad contradictoria con el reconocimiento de la necesidad que cada persona tiene del resto del grupo, lo que significa que, a medida que la individualización va definiéndose como forma de identidad, el reconocimiento de la necesidad de vinculación al grupo como mecanismo generador de seguridad es cada vez más negado en términos explícitos y, por tanto, más actuado a través de mecanismos (como la noción de patrimonio) cuyo significado profundo y trascendental suele ser inconsciente e incluso negado.

En efecto, el sentimiento de fuerte vinculación con el grupo es inherente a la identidad de las personas que pertenecen a sociedades de escasa complejidad socio-económica -como las de los cazadores-recolectores-, pero es contradictoria con la individualidad que caracteriza a la Modernidad. En las sociedades de menor complejidad socio-económica el mecanismo de reforzamiento y seguridad es muy dependiente: la persona no se concibe sin el grupo al que pertenece; y sin una instancia protectora de éste: dios siempre en la base, acompañado y asociado a jefes, señores y monarcas a medida que la sociedad se va haciendo más compleja y avanzamos en el proceso histórico. Por eso, hasta la modernidad, los monumentos eran (y son, en las sociedades pre-modernas actuales) símbolos de esas instancias, sólidos emblemas del poder sagrado o idealizado que protege al grupo, materializaciones icónicas de la capacidad de permanencia, de la resistencia desde el pasado y por tanto en el futuro, de aquellas instituciones a quienes representan.

Pero a partir del siglo XVII se consolidó dentro de nuestra trayectoria histórica una forma de identidad cuyos rasgos habian ido apareciendo gradualmente, a medida que la sociedad desarrollaba mayor división de funciones y especialización del trabajo: la individualidad. Sólo en el siglo XVII comenzó a aplicarse el concepto de "individuo" a las personas (ELIAS, 1990 a: 185; MAUSS, 1991: 323; WEINTRAUB, 1993: 49) porque sólo entonces un número significativo de hombres (que no de mujeres) comenzó a sentirse con suficiente capacidad de 


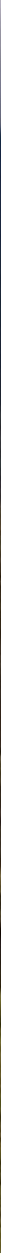

En sociedades de menor complejidad socio-económica el sentimiento de vinculación con el grupo es inherente a la identidad de las personas. Restos de la ciudad inca de Machu Pichu, Perú. Foto: Olivier Taillon

controlar materialmente el mundo a través de la tecnología y de explicarlo a través de la razón como para percibirse a sí mismos como instancias autónomas de identidad, agentes de su propio destino. Esta percepción de uno mismo fue consolidándose hasta que, con la Revolución Industrial, la convicción de que el ser humano tenía la capacidad de decidir su futuro a través de su iniciativa y su trabajo abrió la puerta a la posibilidad de prescindir de dios por primera vez en la historia. Sólo en la Modernidad la condición de "grupo elegido" deriva no del privilegio de haber sido escogido por un agente sagrado, sino de la autocomplaciente percepción de nuestra auto-suficiencia frente a los demás grupos humanos: nuestro grupo tiene más posibilidades de supervivencia porque sabe cambiar, y de hecho, cada cambio marca un avance en nuestro control del mundo. El mundo ya no es, desde la Modernidad, el resultado de acciones divinas de cuya permanencia e inalterabilidad depende la supervivencia humana, sino el resultado de cambios determinados por el propio ser humano (HERNANDO, 2006).

El problema es que la sensación de potencia, autonomía y autosuficiencia que son inherentes a la individualidad constituyen una mera fantasía, porque es un hecho que cada uno de nosotros no puede sobrevivir si no es en intima cooperación con el resto del conjunto. Paradójicamente, mientras un cazador-recolector (un indio del Amazonas, por ejemplo, o un bosquimano, o un aborigen australiano) no puede imaginarse sino como parte de su grupo y, sin embargo, es perfectamente capaz de sobrevivir sin él -pues en su sociedad no hay división de funciones ni especialización del trabajo, de forma que todos saben hacer todo lo que es necesario para sobrevivir-, en nuestra sociedad, en cambio, nos imaginamos constantemente como unidades aisladas, núcleos de identidad independiente, "individual" $y$, sin embargo, no somos capaces de sobrevivir sin el grupo, porque la división de funciones es tan elevada, que exige la colaboración entre muchos para generar las condiciones de supervivencia de cada cual. Es decir, la individualidad implica la convicción de que cada uno de nosotros somos instancias completas e independientes de identidad y existencia; pero eso es una fantasía que no puede extenderse más allá de un determinado límite, pasado el cual se nos haria obvia nuestra impotencia y nuestra pequeñez frente al mundo, y la angustia reduciria nuestra capacidad de supervivencia. Por eso, cuando ese límite está a punto de alcanzarse, lo que sucedió al comienzo de la Modernidad, empiezan a generarse mecanismos que sirven para reforzar nuestro sentimiento de pertenencia al grupo, que nos recuerdan que existe una instancia que nos protege y nos da seguridad. Al igual que la propia idea de patria-nación, el concepto y la protección del patrimonio cultural forman parte de ese tipo de mecanismos y por eso aparecen a la vez. Pero a diferencia del papel que atribuye a dios quien cree en él, o que se atribuia a los señores feudales o a los monarcas en etapas pre-modernas, nadie identifica de forma consciente el patrimonio con esa función, porque ha pasado a "actuarse" a través de la negación que exige la individualidad como forma de identidad. 


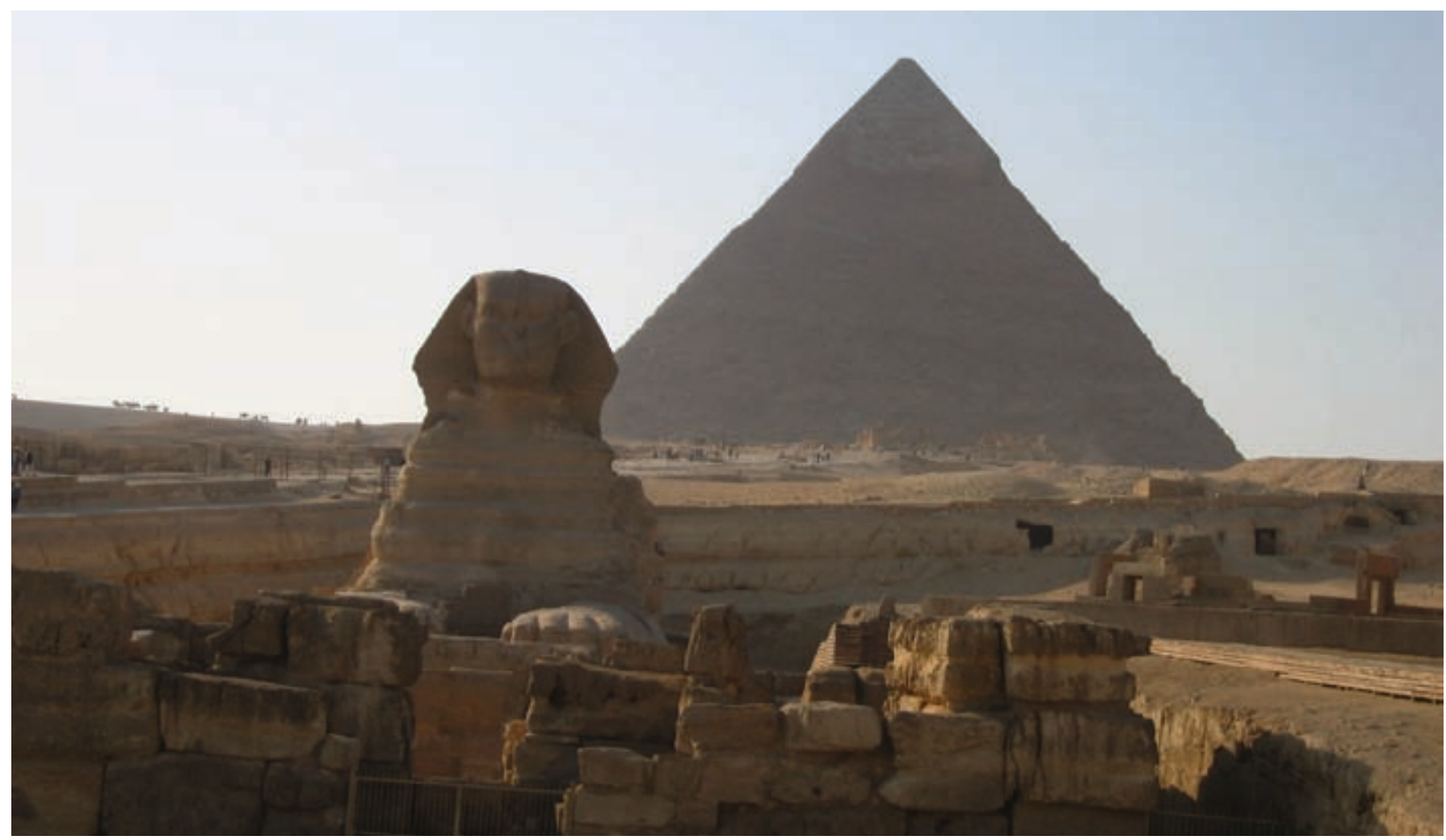

Hasta la Modernidad, los monumentos eran símbolos de poder que reflejaban la capacidad de permanencia de todos los entes superiores. Esfinge y pirámide de Kefrén, El Cairo (Egipto). Foto: Daniel Villoldo

\section{MECANISMOS DE VINCULACIÓN AL GRUPO EN LOS GRUPOS DE ESCASA COMPLEJIDAD SOCIO-ECONÓMICA}

Para entender la función que el patrimonio cultural representa en nuestra sociedad, conviene comenzar por analizar el tipo de recursos que utilizan los grupos de menor complejidad socio-económica para sentir que están seguros y que controlan el mundo en el que viven, a pesar de que, como sabemos, son los que menor control material tienen de sus condiciones de vida. Decir que un grupo tiene escasa complejidad socio-económica significa decir que no tiene división de funciones (salvo la marcada por el género) ni especialización del trabajo. Esto implica, por un lado, que tiene un escaso dominio y capacidad de control de la naturaleza no humana (de las nubes, ríos, montañas, animales, etcétera) y por otro, que los comportamientos de las personas son muy semejantes entre sí, diferenciándose básicamente sólo en función del género. En estos grupos, las personas se sienten muy iguales entre sí, porque en una gran medida lo son, por lo que no se perciben unas a otras como fuentes de amenaza o riesgo. A cambio, sin embargo, la naturaleza no humana (los ríos, las nubes, las montañas, etcétera) es percibida como una constante fuente de amenaza, pues no se han descifrado las leyes que rigen sus mecánicas ni, por tanto, pueden anticiparse o preverse sus efectos. Así que la identificación entre sí de estas personas como miembros del grupo al que pertenecen constituye un mecanismo natural de refuerzo de la identidad, de sensación de protección y seguridad (ELIAS, 1990 a: 143). Por ello, su identidad no está individualizada. Su identidad no se basa, como en nuestro caso, en lo que diferencia a unas personas de otras, sino en lo que las asemeja. Una persona sabe quién es porque es parte del grupo al que pertenece, porque es como el resto del grupo, siendo la instancia última de identidad el grupo y no la persona, lo que se visibiliza a través de una apariencia común de todos los miembros de la sociedad mediante todo tipo de recursos de ornamentación y de expresión corporal (VIVEIROS DE CASTRO, 1996). De hecho, estudios sobre el concepto de persona en estos grupos indican que, aunque existan palabras para denominarse a uno mismo, así como sufijos y mecanismos verbales que expresan la relación entre el sujeto que habla y el objeto del que lo hace (MAUSS, 1991: 310; ELIAS, 1990 a: 123), uno/a sólo puede concebirse a sí mismo/a como parte de una relación: soy el padre de mi hijo, la hija de mi madre, el hermano de mi hermana, etcétera (LEENHARDT, 1997: 153).

Al mismo tiempo, cuando no hay división de funciones ni especialización del trabajo no se ha desarrollado la escritura ni leyes científicas que permitan entender las mecánicas de funcionamiento de la naturaleza, por lo que se atribuye a ésta el único comportamiento que se conoce: el comportamiento humano. Ahora bien, al mismo tiempo, se percibe a la naturaleza no humana como detentadora de un poder muy superior al de la naturaleza humana, pues tiene la capacidad de dar y quitar la vida, de fortalecer o arruinar las cosechas, de provocar enfermedades o de favorecer su cura, por lo que se la sacraliza. Por eso la vida y sus avatares se explican en función de los deseos o caprichos, de las iras y generosidades de una instancia sagrada de dinámica humana integrada por los montes o las nubes, que se comunican permanentemente con los humanos cuyas vidas determinan. Este tipo de relación con la realidad es la que caracteriza a los mitos (ELIADE, 1988: 86; DOUGLAS, 1991: 97). En estas sociedades, el ser humano se siente parte de una comunidad de afectos y vínculos personales 


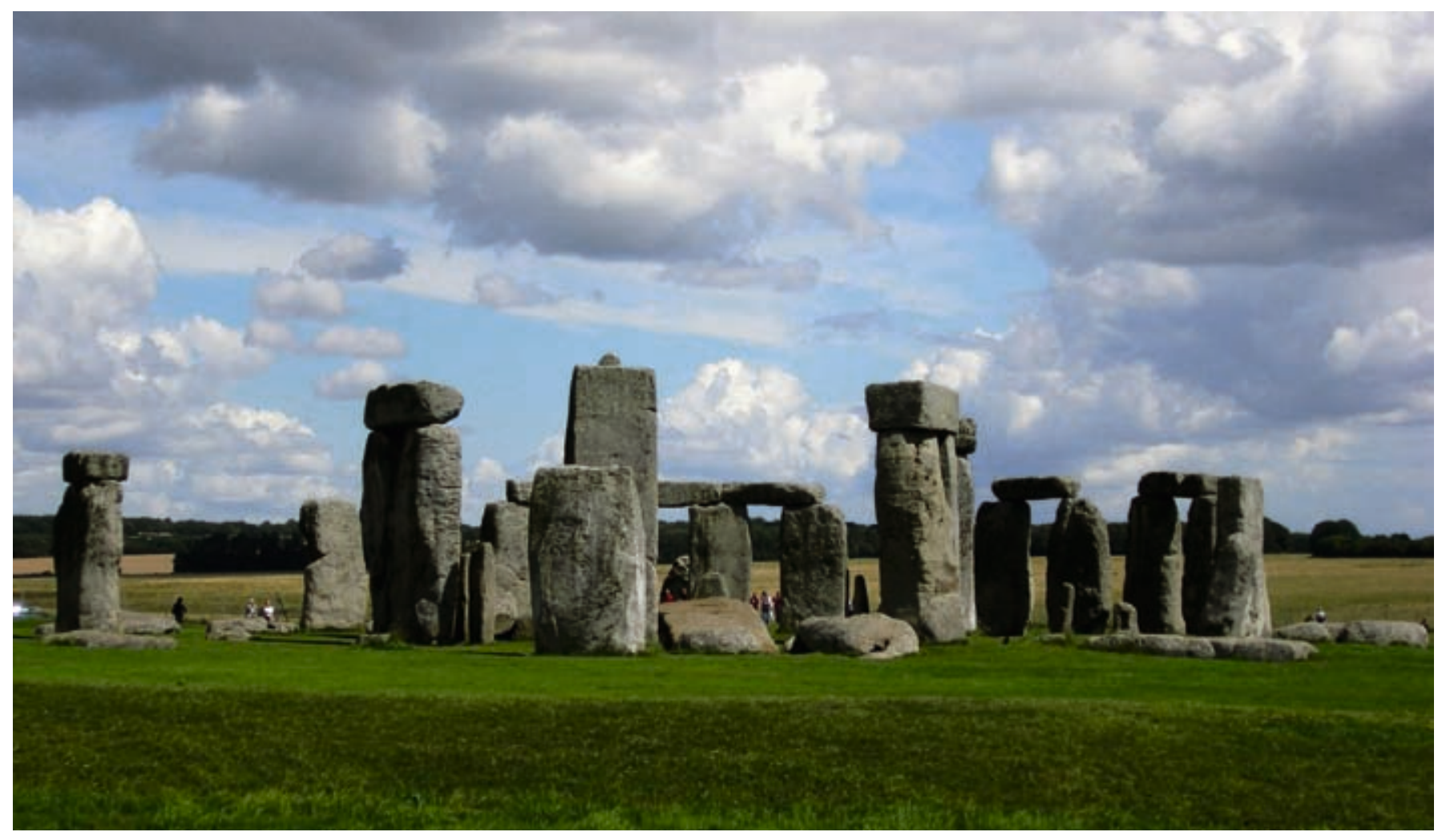

En la Antigüedad la seguridad de las diferentes sociedades deriva del convencimiento de estar bajo la protección de una instancia sagrada, y es a través de los ritos como se relacionan con lo divino. Crómlech de Stonehenge, Amesbury (Gran Bretaña). Foto: Salvador Busquets

que se extienden a todo fenómeno vivo de la realidad. En ellas, no se objetiva el mundo, porque todo fenómeno se interpreta en clave de interrelación personal. El ser humano se siente profundamente conectado con toda la naturaleza. Es el modo de identidad más gratificante que existe, el que más colma emocionalmente (HERNANDO, 2000; 2002), aunque su condición sea no comprender las mecánicas de funcionamiento del mundo, y por tanto, la impotencia, la falta de control material sobre él. Sin embargo, esa impotencia no es percibida de forma consciente. Por el contrario, estos grupos se sienten completamente seguros en la realidad en la que viven, lo que tiene que ver, precisamente, con el carácter sagrado que atribuyen a la naturaleza no humana. Dado que no han desarrollado la escritura, ni por tanto mapas o sistemas abstractos de representación espacial del mundo, sólo pueden ordenar aquella parte de la naturaleza por la que han andado y en la que han vivido, pues serán sus árboles, rocas o montañas, las que les sirvan como referencias para orientarse en la realidad. El resto del mundo no se puede ni imaginar, porque no existen instrumentos para representarlo. Asi que estos grupos creen que viven en el único mundo ordenado, en el único que tiene sentido, en el único que no es caos (ELIADE, 1988; HUGHES, 1995: 8). Además, como han proyectado su propio comportamiento a toda la naturaleza, entienden que ellos son los únicos seres humanos que se comportan como la naturaleza, esto es, como la instancia sagrada en cuyo seno viven y gracias a la cual sobreviven. Es decir, se construye a la divinidad a imagen y semejanza del grupo y luego se interpreta que la divinidad ha hecho al grupo a su imagen y semejanza, que lo ha elegido entre todos los demás, para hacerle depositario del verdadero orden del mundo, del orden que permite sobrevivir. De ahi que todos los seres humanos que se relacionan con la realidad a través de los mitos crean siempre que son el "pueblo elegido", y de ahí, que la denominación que se auto-conceden los grupos cazadores-recolectores y horticultores, los de menor complejidad socio-económica, signifique siempre algo así como "los seres humanos auténticos" o "los hombres verdaderos" (VIVEIROS DE CASTRO, 1996; ELIADE, 1968). De esta forma, su impotencia material y tecnológica se neutraliza con un potentísimo sentido de privilegio y protección frente al mundo. Son los grupos que más seguros se sienten, los más estables emocionalmente porque, además, ellos no perciben su impotencia o falta de control material como una desventaja, ya que nunca buscan los cambios, que implican riesgos dado su escaso nivel de complejidad socio-económica. La seguridad que sienten deriva, precisamente, del convencimiento de que la instancia sagrada les mantendrá el privilegio de hacerles partícipes de su orden y les seguirá protegiendo siempre que ellos sigan respetando ese orden y no cambien, siempre que reconozcan su poder y que humildemente se rindan a su superioridad. Por eso, el mito siempre se asocia al rito como forma imprescindible de relación con lo sagrado. Lo importante en el rito no es la forma que adopte, sino la repetición que representa, la exhibición de respeto y sumisión al poder sagrado en cuyas manos se encuentra el destino del grupo.

En consecuencia, para estos grupos, el presente no se explica o legitima a través de los cambios en el pasado, sino precisamente a través de la ausencia de éstos, y de la sensación de que respetan y mantienen inalterado el modo de vida transmitido por la instancia sagrada que les protege. Mientras nuestra sociedad se caracteriza por el constante cambio, el deseo perpetuo de transformación, la suya lo hace por la repetición, el desesperado deseo de per- 


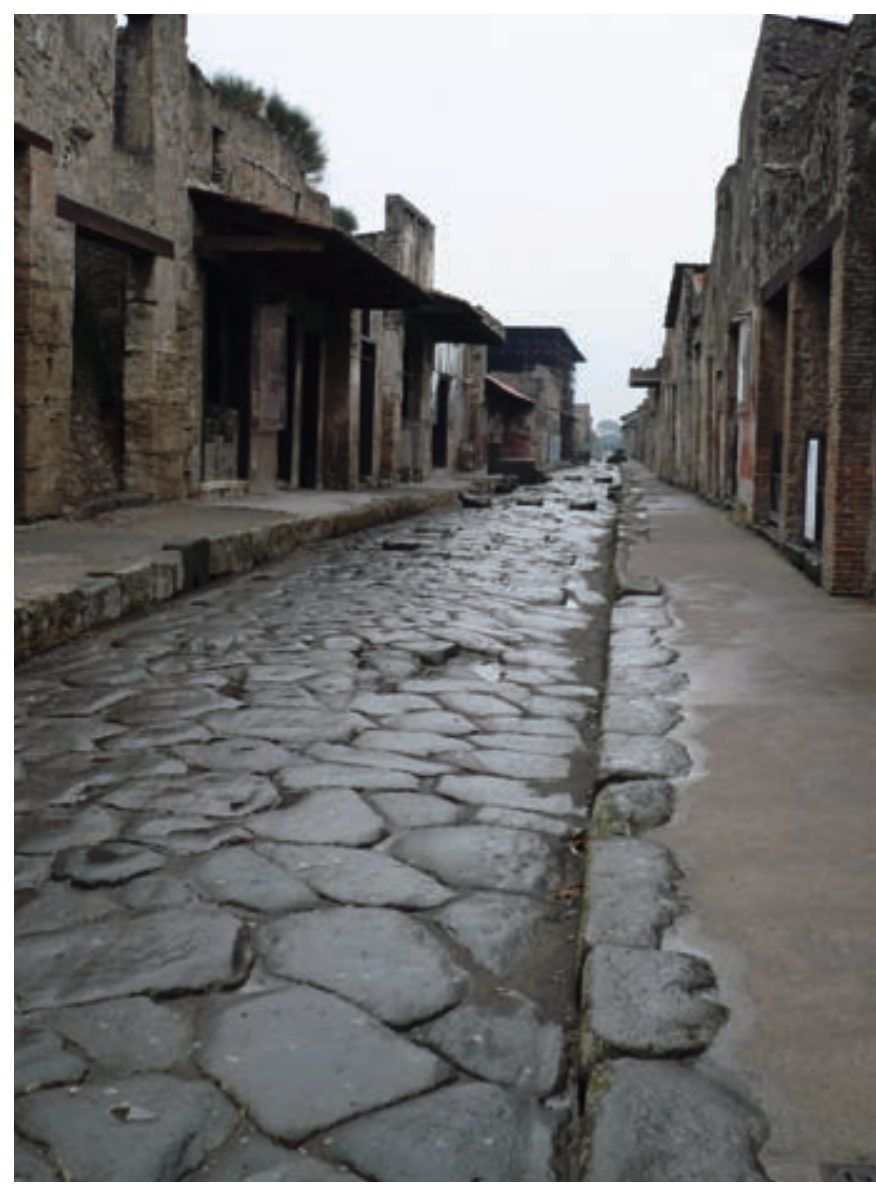

Los grandes descubrimientos arqueológicos transformaron el relato mítico de los orígenes de la civilización en uno científico, organizado a través de los cambios. Ruinas de Pompeya, Italia. Foto: Joan Grífols

manencia de lo mismo. Al contrario que nosotros, que aspiramos a construir un presente a la medida del futuro que imaginamos, ellos aspiran a construir un futuro a la medida del presente que conocen. Cualquier otra posibilidad entraña riesgo y, por tanto, se descarta. Por eso, la memoria se organiza en clave espacial y no temporal (HERNANDO, 2002: 93), porque favorece la idea de permanencia y transmite la sensación de un tiempo sin cambios. De esta forma, el pasado se construye a través de espacios míticos, paralelos o superpuestos al de la naturaleza material, tal y como siguen siendo el Cielo o el Infierno, por ejemplo, en nuestra propia tradición cultural. Cuando comienza a aumentar la complejidad socio-económica del grupo en cuestión, y ya existe alguna experiencia de cambio en las propias actividades pero aún no hay escritura, además de esos espacios en donde habita la memoria de lo eterno, lo fundacional, estos grupos recuerdan hechos particulares de su pasado como mecanismo añadido de cohesión, de experiencia compartida que da sentido al presente común. Y esta memoria sigue organizándose en clave espacial, anclándose a referencias topográficas, convirtiendo el paisaje en memoria (SANTOS GRANERO, 2004: 203; RAPPAPORT, 2004: 177). Todos los autores que estudian la percepción del espacio en grupos de estas características coinciden en que suele producirse una identificación entre la acción que se recuerda y el espacio donde aconteció (HOBBS, 1992; THORNTON, 1980; DIETLER Y HERBICH, 1993; BOURDIEU, 1980; SKAR, 1981). En este sentido, resulta interesante el concepto de "escritura topográfica" que Santos Granero (2004)

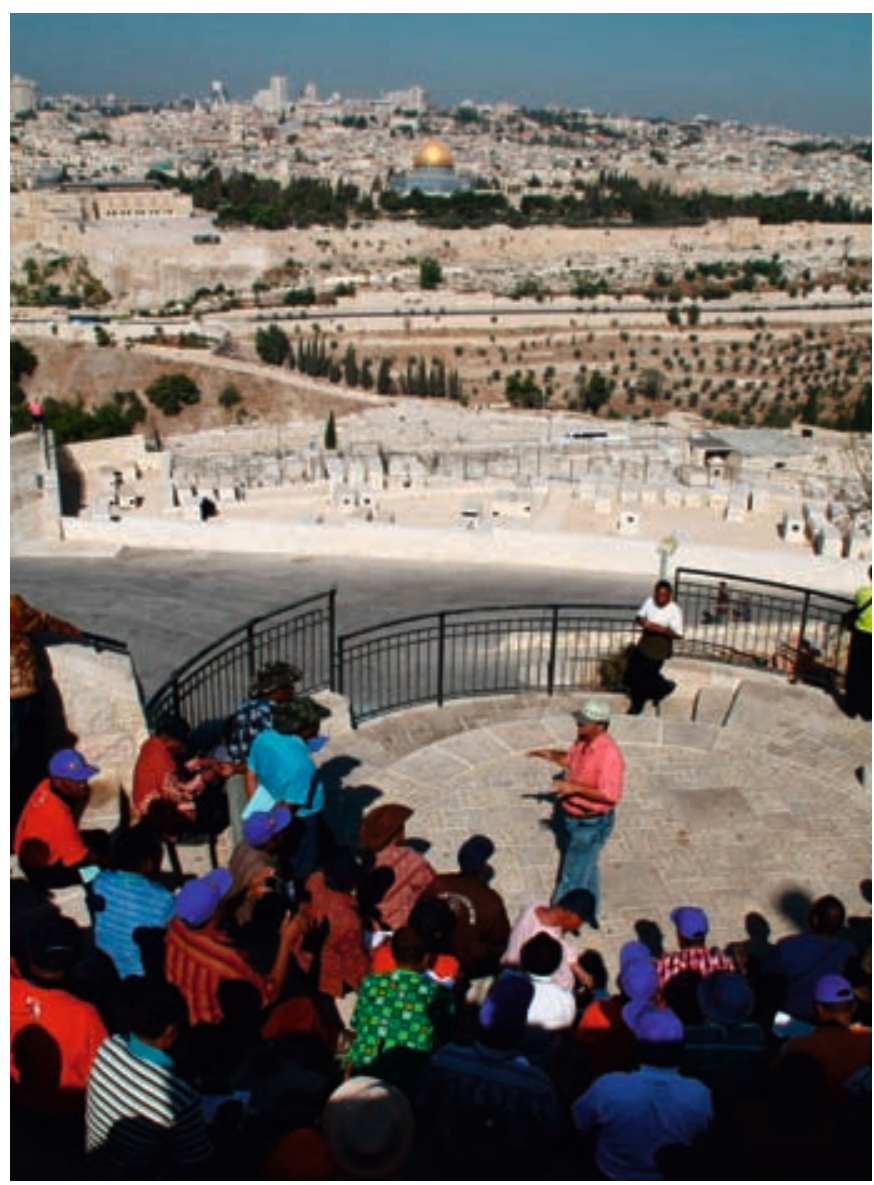

El patrimonio cultural elige las obras más destacadas de nuestro pasado y las convierte en símbolos de nuestra esencia. Jerusalén, Israel. Foto: Víctor Fernández Salinas

utilizó para referirse a este tipo de anclajes de la memoria: Ios yanesha a los que él estudiaba asociaban los hechos que recordaban a un hito espacial junto al que habian acontecido. Es decir, al pasar junto a una montaña, un río o una roca recordaban sucesos que habian ocurrido allí. Esta "historia", como ocurre también en el caso de los Nasa, "obedece a una organización espacial, tiene una explicación cronológica y las alusiones a ella se encuentran en referentes geográficos, en vez de aparecer directamente en el orden de la narración" (RAPPAPORT, 2004: 182). Lo importante es recordar los hechos, porque es su existencia lo que resulta relevante memorizar, no el orden de su sucesión. Santos Granero (2004: 209) comparaba ese tipo de lectura de la "historia" con la del Via Crucis cristiano, en que cada evento de una secuencia se recuerda a través de una referencia espacial. Sólo cuando el cambio deja de valorarse como un riesgo y comienza a constituir la clave en la que se cifra la seguridad, el pasado comienza a ordenarse en términos temporales y no espaciales. Y eso sólo ocurrió en la Modernidad.

En efecto, a medida que fue produciéndose un aumento de la complejidad socio-económica, fueron desacralizándose aquellos fenómenos sobre los que comenzaba a ejercer un control. El poder humano empezó a considerarse superior al de la naturaleza no-humana en todos aquellos ámbitos en que se ejercía dominio sobre ella, lo que hacía también que el poder humano comenzara a considerarse una fuente de protección y cobijo, una instancia 
de fuerza y seguridad. La individualidad definió progresivamente la identidad de los miembros del grupo social (o al menos de los hombres, en un primer momento), a medida que las actividades se multiplicaban y la escritura se generalizaba, así que el tiempo iba ordenando sucesos cada vez más cambiantes y el espacio partes de la naturaleza cada vez más lejanas, nunca visitadas por el grupo, pero introducidas en mapas que se sabía interpretar. A medida que la sociedad iba experimentando el cambio como parte de sus actividades cotidianas y vitales, iba dejando de considerarlo un riesgo, y por el contrario, comenzaba a considerarlo condición de progreso. De hecho, poco a poco, el grupo humano iba dejando de considerar que su garantía de supervivencia consistía en mantener inalterado el modo de vida que la instancia sagrada le habia transmitido, y empezaba a pensar que residia en su propia capacidad de cambio y de transformación. Asi que, a medida que la individualidad y el control tecnológico del mundo avanzaban, la memoria empezaba a construirse a través de referencias temporales, y la Historia -relato de cambios en el tiempo representados a través de la escritura y de las elaboraciones abstractas que permite- sustituía progresivamente al Mito -relato de permanencias visibilizadas a través de monumentos y elementos en el espaciocomo discurso de legitimación del presente.

\section{EL PATRIMONIO COMO MECANISMO DE VINCULACIÓN AL GRUPO SOCIAL EN LA MODERNIDAD}

Y así, poco a poco, se fue llegando a la Modernidad, cuando la sociedad que protagoniza la revolución industrial comienza a sentir definitivamente que su seguridad en el mundo deriva del control material que le permite el desarrollo de la razón técnica, y no de instancias de poder superior, divino o humano. Darwin, Marx o Freud comienzan a elaborar nuevos relatos de la realidad cuyo eje vertebrador es el cambio, de forma que se va legitimando la idea de que el cambio, ese cambio que ya la sociedad experimenta como parte de su cotidianidad, es fundamental para su supervivencia, porque le ha permitido construir un presente en el que se siente más fuerte y segura que en el pasado. Por eso los planteamientos evolucionistas y positivistas caracterizan los primeros desarrollos científicos, y por eso la Arqueología aparece en ese momento, como mecanismo fundamental de creación de las nuevas formas modernas de identidad socio-politica (HERNAND0, 2002; 2006). A través de los objetos, de las evidencias materiales de un pasado distinto, se transforma el relato mítico de los orígenes, basado como todos los mitos en un espacio ideal, el Paraíso donde Adán y Eva fueron creados por Dios a su imagen y semejanza, en uno científico, es decir, en uno organizado a través de los cambios y leido a través del tiempo, que viene a sustituir al espacio como eje fundamental sobre el que ordenar la realidad. Y paralelamente a todo ello, comienza a generarse, desde las nuevas instituciones de la Modernidad -aquellas que encarnan el cambio y la individualidad- el concepto de Patrimonio Cultural. ¿Cuál podía ser su función en este recién estrenado escenario de la Modernidad?
Como todos sabemos, la identidad moderna es muy contradictoria. La "desmitificación" del Universo y la comprensión científica de sus fenómenos nos fue otorgando a los integrantes de la sociedad occidental unos márgenes de seguridad a los que no queríamos renunciar, pero al tiempo, este modo de relación con la realidad nos iba situando en una posición más responsable y más solitaria cada vez. El proceso de aumento de conocimiento objetivo de la realidad suponía una pérdida de importancia del ser humano dentro de su propia visión del mundo, es decir, se caracterizaba por un antropocentrismo cada vez menor (ELIAS, 1990 b: 93; DOUGLAS, 1991: 95). Fuimos dejando de creer que el mundo había sido diseñado para nosotros por dioses que nos habian "elegido" para ser los únicos privilegiados por su presencia y su orden. Poco a poco, el alejamiento emocional que la ciencia implica, nos fue enseñando que el universo no se había hecho para dar cabida a nuestro grupo social, y luego, que el sol no se habia hecho para girar alrededor de la Tierra, y más tarde, que el Universo tenía sus propias leyes de funcionamiento que convertian a la Tierra en un elemento del todo prescindible para su existencia. El ser humano era cada vez más prescindible, más irrelevante, menos protagonista, aunque a cambio, cada vez controlaba más la realidad en la que vivia (ELIAS, 1990 b: 95).

Los humanos íbamos pagando crecientes precios emocionales por aumentar ese control. Porque, como hemos visto, entender la mecánica de un fenómeno implica desacralizarlo, es decir, objetivarlo, convirtiendo en una relación sujeto-objeto aquello que hasta entonces había sido una relación personal. Así que comprender el mundo significa perder vínculos emocionales con él. Cuanto mejor se entiende el Universo, cuanto más poder se tiene sobre él, más solo se va sintiendo el ser humano, menos protegido, menos reforzado por vínculos y afectos. Además, una identidad más individualizada implica un correlativo aumento de la ansiedad, ya que su estructura de construcción exige ampliar y perfeccionar constantemente los modelos de representación del mundo, "entenderlo" mejor, conocerlo más. Desde la infancia nos definimos por lo que llegaremos a ser, no por lo que ya somos por el simple hecho de existir, y sólo la muerte parece justificar el descanso, la parada, la llegada definitiva a ningún lugar. No podemos parar, porque entendemos el cambio como la condición de la vida, al contrario que un cazador-recolector, que lo considera la condición de la muerte. Nuestra identidad se basa cada vez más en un "yo" encapsulado y conflictivo, en un tipo de relación con el mundo que implica tanta más distancia emocional cuantos más fenómenos se entienden a través de la "razón". Es ya difícil que nos "identifiquemos" plenamente con otros miembros del grupo, que vinculemos nuestra identidad a otra persona. De hecho, nuestros comportamientos y los tipos de relación que sostenemos son ya tan diferentes y se dan a tantos niveles distintos, que hemos aprendido a calcular el alcance que le podemos dar a la expresión de nuestras emociones en cada momento, por lo que sólo cada uno de nosotros sabe todo lo que en realidad hay en su propio interior. Como no sabemos lo que los demás "esconden", las personas son cada vez más el origen de nuestros temores, el lugar donde reside la amenaza, que en 


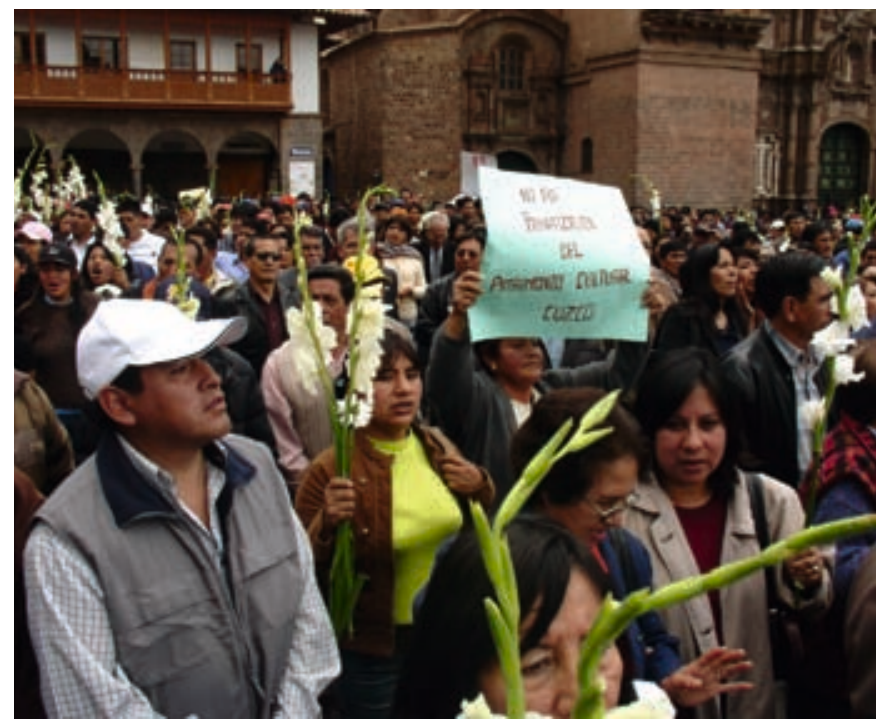

En la actualidad el patrimonio es entendido como un bien que hay que conservar por y para la comunidad. Manifestación en contra de la privatización del patrimonio cultural en Cuzco, Perú. Foto: Walter A.

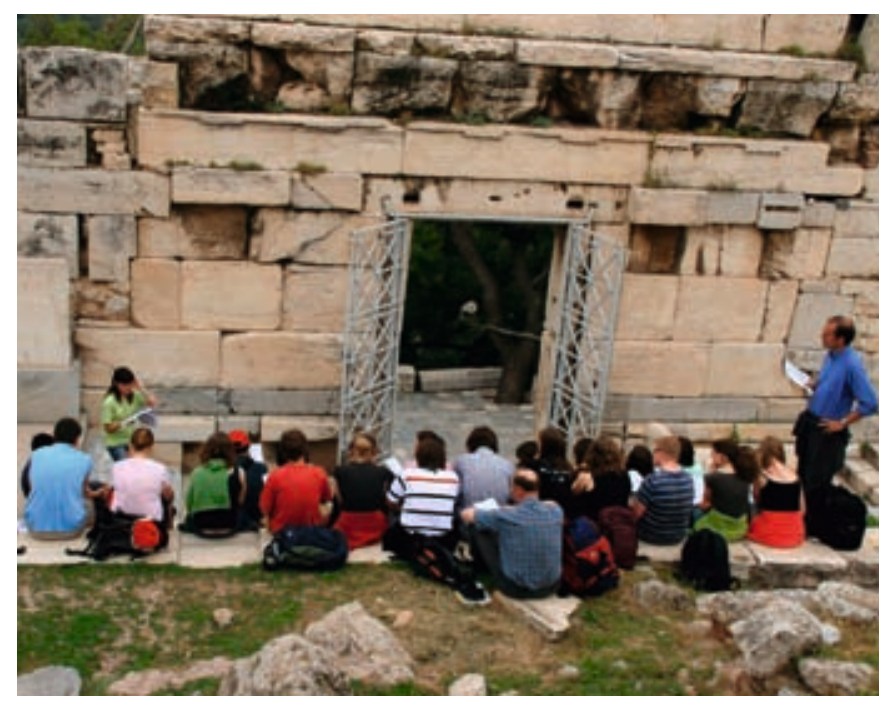

Es de esperar que la importancia del patrimonio se incremente en proporción directa a la intensificación de los rasgos de individualidad que definen la identidad posmoderna. Acrópolis de Atenas, Grecia. Foto: Víctor Fernández Salinas

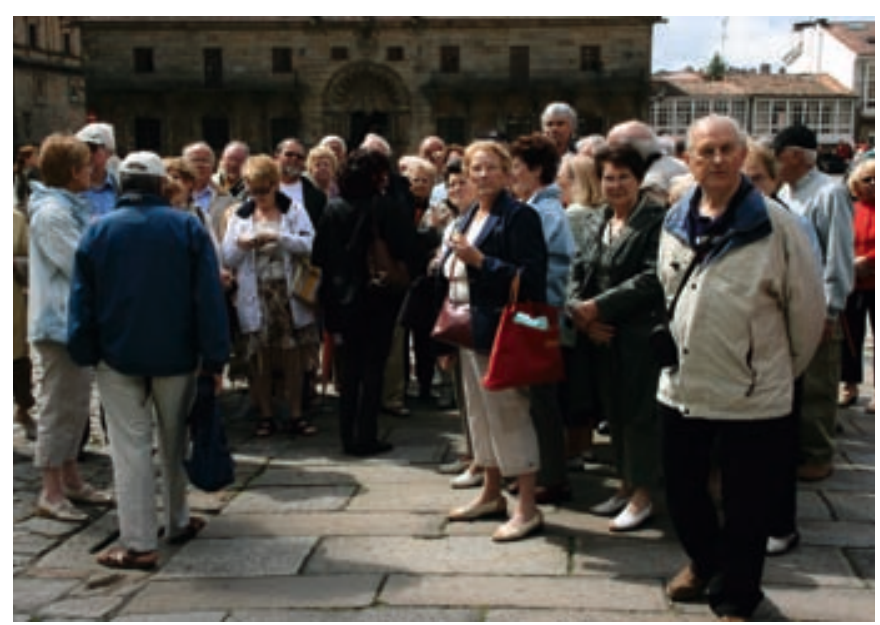

El patrimonio sirve para recordar que formamos parte de una unidad mayor que nosotros mismos, que nos vincula y nos hace fuertes. Plaza del Obradoiro, Santiago de Compostela. Foto: Víctor Fernández Salinas virtud de nuestro progresivo desarrollo tecnológico y científico, hace tiempo además que dejó de localizarse en la naturaleza no humana (ELIAS, 1993: 504). Vivimos en una sociedad muy poco gratificante en términos emocionales, tan aparentemente seguros de nuestra trayectoria social y cultural como descarnadamente inseguros en nuestras respectivas trayectorias personales.

De esta forma, los mecanismos de la identidad, cuyo fin esencial es hacernos sentir seguros en el mundo, podrían haber comenzado a verse inmersos en una trampa sin salida al comienzo de la Modernidad: de haber seguido la trayectoria lineal de transformación, la realidad material del aumento del control técnico del mundo se habría visto enfrentada a una realidad emocional de sensación de soledad y pérdida del sentido vital de las personas que tenían ese control. Porque a medida que iban entendiendo el mundo, dejaban de encontrarle sentido, ya que no lo podian sentir, sino sólo pensar. Y eso, paradójicamente, habria hecho inoperante nuestra cultura, habria hecho que nos sintiéramos los seres más desorientados del mundo a pesar de ser los que más control habíamos alcanzado sobre él. Si eso no sucedió, no está sucediendo y presumiblemente no sucederá en el futuro, es porque cuando la individualidad se convirtió, después de un largo proceso histórico, en el modo de identidad generalizado dentro del grupo social (o al menos entre los hombres que detentaban el poder), esos mismos individuos comenzaron a desarrollar mecanismos neutralizadores del aislamiento emocional que implicaba.

Ahora bien, si se trataba de potenciar la sensación de pertenencia a la comunidad, de vínculo emocional y de confianza en que no estaban solos, entonces esos mecanismos tendrían que adoptar la estructura de los mitos: había que mantener la confianza en que existe una instancia superior que nos protege y de la que deriva nuestro orden social, una instancia generadora de identidad, con la que nos identificamos, que nos permite reconocernos a su imagen y semejanza, con la que conectamos emocionalmente y que, por tanto, es fuente de sentido. Pero esa instancia ya no podía ser dios, porque ahora entendiamos racionalmente el mundo en el que antes le haciamos residir, ni jefes que determinaran nuestro destino, porque la individualidad se basa, precisamente, en el sentimiento de autonomía en el mundo, de no subordinación... Así que tenía que ser una instancia donde ya no cupiera la jerarquía ni la subordinación, pero en la que, como todas las instancias protectoras que sirven para aglutinar a un grupo humano, reconociéramos nuestra esencia, aquello que consideramos que nos diferencia de los demás, que nos lleva a pensar que somos los "elegidos" del destino, porque conocemos lo que los demás desconocen, el verdadero orden del mundo, el que permite sobrevivir. Y nuestra esencia, lo que nos diferencia de los demás grupos humanos, lo que hace creer a la mayoría que, en realidad, nosotros si que somos los "seres humanos auténticos", es la convicción de que el secreto de la supervivencia reside en la capacidad de cambiar, y que por tanto, nuestra permanencia estará garantizada, paradójicamente, si seguimos cambiando. Nuestra instancia protectora no podia ser ya más que la imagen del propio conjunto social, soste- 
nido y reforzado a través de los cambios sufridos en su trayectoria histórica. Y eso es lo que representa el Patrimonio Cultural. Elige las obras más destacadas de nuestro pasado y las convierte en símbolos de nuestra esencia: representan nuestras capacidades, nuestra sensibilidad, nuestros logros, lo mejor que ha sabido dar una cultura que se ha construido a través de los cambios, que se ha ido nutriendo de cambios, que ha encontrado en los cambios el secreto de su supervivencia. Por eso, a diferencia de los demás mitos de origen, que niegan sus constantes reactualizaciones, el Patrimonio se caracteriza, precisamente, por exhibir la interminable reactualización de nuestra esencia a través de los cambios evidenciados por los monumentos y materiales del pasado que distintas disciplinas científicas (Arqueología, Historia, Etnología, Historia del Arte) se han encargado previamente de fechar y de estudiar. Pero a diferencia de esas disciplinas, que construyen la memoria a través de referencias temporales, elaboradas a través de la escritura y las cronologías, y dan cuenta de lo que fuimos y ya no somos, el Patrimonio utiliza los objetos y monumentos que ellas fechan para organizar nuestra memoria con referencias espaciales $y$, de esta manera, con la estructura consustancial a los mitos, hablar de esencias, de permanencias, de lo que queda y por tanto seguimos siendo, de lo que hace fuerte a nuestro grupo y lo distingue de los demás. El Patrimonio Material constituye una suerte de "escritura topográfica", al modo de las montañas o las rocas en los grupos de escasa complejidad socio-económica, en donde cada referencia espacial se asocia a una parte de nuestra historia, leida en clave espacial y no temporal, porque pertenece a una lógica mítica y no científica.

Y como esas montañas y rocas a los cazadores-recolectores, los megalitos a los primeros campesinos, o las iglesias, mezquitas o sinagogas a quienes se acogen a la protección divina en las sociedades con escritura, el Patrimonio sirve para recordar (aunque no sea de forma reflexionada ni tan siquiera consciente) a quienes hemos desarrollado la individualidad más allá de un determinado limite, que existe un "nosotros" que nos vincula y nos hace fuertes; que somos algo más que lo poco que nos sentimos a pesar de pretender que controlamos el mundo; que formamos parte de una unidad mayor que nosotros mismos a pesar de lo solos que nos sentimos cuando comprendemos ese mundo, porque en realidad cada uno de nosotros somos también el grupo al que pertenecemos. $Y$ nos convence de que el vertiginoso e incierto futuro que se nos abre cada dia, que nos hace sentir que la sociedad en la que vivimos tiene poco que ver con la que vivíamos hace tan sólo 50 años; que nos hace imposible imaginar cómo será en 50 años más, será un futuro seguro, que tendrá sentido, en el que sabremos sobrevivir, porque nuestro grupo, a diferencia de los demás, sale fortalecido con los cambios. Aunque parezca contradictorio y paradójico, sólo a través de mecanismos colectivos, como el del Patrimonio, es posible sostener esta convicción, que equivocadamente atribuimos a la individualidad. Si no existieran esos mecanismos, nuestra percepción sería la de un futuro desgarrado emocionalmente, tecnológico y frío como el acero, científico y dominador de la materia y la energía, pero sin el calor, el color y la dulzura de la emoción. Y es sólo la emoción la que da sentido a la vida, resultando completamente irrelevante que sus fenómenos se hayan conseguido entender o controlar para "tener ganas" de vivir. De ahi que quepa esperar que la importancia del Patrimonio se incremente en proporción directa a la intensificación de los rasgos de individualidad como definidores de la identidad postmoderna.

\section{Bibliografía}

BABELON, J. P.; CHASTEL, A. (2000) La notion de patrimoine. Paris: Liana Levi, imp. 2000

BOURDIEU, P. (1990) Time perspectives of the Kabyle. En HASSARD, J. (ed.) The Sociology of Time. New York: St. Martin's Press, 1990, pp. 219-237

DIETLER, M.; HERBICH, I. (1993) Living of Luo time: reckoning sequence,

duration, history and biography in a rural African society. World Archaeology 25, 2: Conceptions of Time and Ancient Society, 1993, pp. 248-260

DOUGLAS, M. (1991) [1970) Pureza y peligro. Un análisis de los conceptos de contaminación y tabú. Madrid: Siglo XXI, 1991

ELIADE, M. (1968) Mito y Realidad. Barcelona: Labor, 1968

ELIADE, M. (1988) Lo sagrado y lo profano. Barcelona: Labor, 1988

ELIAS, N. (1990 a) La sociedad de los individuos. Barcelona: Península, 1990

ELIAS, N. (1990 b) Compromiso y distanciamiento. Barcelona: Península, 1990

ELIAS, N. (1993) El proceso de la civilización. Investigaciones psicogenéticas y sociogenéticas. Madrid: Fondo de Cultura Económica, 1993

HERNANDO, A. (2000) Factores estructurales asociados a la identidad de género femenina. La no-inocencia de una construcción socio-cultural. En HERNANDO,

A. (ed.). La construcción de la subjetividad femenina. Madrid: Instituto de Investigaciones Feministas, 2000, pp. 101-142

HERNANDO, A. (2002) Arqueología de la ldentidad. Madrid: Akal, 2002

HERNANDO, A. (2006) Arqueología y globalización. El problema de la definición del "otro" en la postmodernidad. Complutum, no 17, 2006, pp. 221-234

HOBBS, J. J. (1992) Bedouin Life in the Egyptian Wilderness. Austin: University of Texas Press, 1992

HUGHES, D. O. (1995) Introduction. En HUGHES, D.O.; TRAUTMANN, T.R. (eds.). Time. Histories and Ethnologies. Ann Arbor: The University of Michigan Press, 1995, pp. 1-17

LEENHARDT, M. (1997) Do kamo. La persona y el mito en el mundo melanesio. Barcelona: Paidós, 1997

MAUSS, M. (1991) Sobre una categoría del espíritu humano: la noción de persona y la noción del "yo". En Sociología y Antropología. Madrid: Tecnos, 1991, pp. 307-333

RAPPAPORT, J. (2004) La Geografía y la concepción de la Historia de los Nasa. En SURRALLÉS, A.; GARCÍA HIERRO, P. (eds.). Tierra adentro. Territorio Indígena y percepción del entorno. Copenhague: IWGIA, Doc. n³9, 2004, pp. 173-185 SANTOS GRANERO, F. (2004) Escribiendo la Historia en el Paisaje: Espacio, mitología y ritual entre la gente Yanesha. En SURRALLÉS, A.; GARCÍA HIERRO, P. (eds.). Tierra adentro. Territorio Indígena y percepción del entorno. Copenhague: IWGIA, Doc. №39, 2004, pp. 187-217

SKAR, S. (1981) Andean women and the concepto f space/time. En ARDENER, S. (ed.). Women and Space. Ground Rules and Social Maps. London: Croom Helm London in association with the Oxford University Women's Studies Comité, 1981, pp. 35-49

THORNTON, R. J. (1980) Space, Time and Culture among the Iraqw of Tanzania. New York: Academic Press, 1980

VIVEIROS DE CASTRO, E. (1996) Os pronomes cosmológicos e o perspectivismo amerindio. Mana, 2(2), 1996, pp.115-144

WEINTRAUB, K. (1993) La formación de la individualidad. Autobiografía e Historia. Madrid: Megazul-Endymion, 1993 